\title{
Some Critical Issues in Social Ontology: Reply to John Searle
}

\section{TONY LAWSON}

Keywords: emergence, language, reducibility, corporation, money

\section{INTRODUCTION}

In my original paper I compared John Searle's conception of social ontology with my own. I concluded that in their basics the two accounts share a significant degree of overlap, albeit with these basics expressed in very different terms. However, I also suggested that Searle's conception does not go far enough. Specifically, although Searle seemingly often presupposes an account of emergent totalities and a founding role to human practices other than language use, these remain, at best, implicit and under-examined.

In his typically robust and insightful reply, for which I am very grateful, Searle views things somewhat differently. Specifically, he appears to interpret various aspects of those parts of my account that I believe parallel his as deficient, and he is dismissive of most additional features of my conception, supposing them to rest on an untenable thesis that emergence is an explanatory notion.

I do not have space to address all of Searle's critical comments here, so I concentrate on issues I believe lie at the heart of our differences.

\section{CONDITIONS OF ADEQUACY OF A THEORY OF SOCIAL ONTOLOGY}

Searle begins his reply suggesting various criteria that an adequate account of social ontology must be able to satisfy. Most especially he asserts that a 'theory must clearly state the differences between human and animal societies', and he supposes that my theory lacks the resources to do this.

Of course, according to my conception, the unique and defining feature of social reality is that its existence depends necessarily upon human beings and their interactions. 'So the social world is already generatively different to the non-human animal world in its basic conception. Searle, however, clearly expects more than 
this. His entry point is that human and animal worlds are in fact substantively very different in observable ways and he insists that a conception of social ontology provide an analysis and explanation.

Searle himself meets his central criterion of theory adequacy as follows:

"The unique feature that humans have, as opposed to other animals, is that they have status functions. The key to understanding human civilization is understanding status functions" (Searle, 2016, p. 6)

If it is indeed a fact that only humans, not other animals, have status functions, this is a feature that my conception can of course accommodate. Certainly I have no problem with the idea that humans have status functions. Specifically, the work done by the category 'status functions' in Searle's account is achieved by way of the use of notions of 'positions and associated system functions' in my own. Thus, it is precisely through using the framework of social positioning that (in the manner of Searle's use of status functions) it is feasible to explain all of Searle's examples from Barack Obama being the US president to Searle being a member of the Squaw Valley Ski Club. In all cases, the identity and associated deontic powers come with positioning, with, in all cases, everything depending on 'collective recognition that an object or person has a certain status, and with that status, a function that can only be performed because of that recognition' (ibid, p. 6).

Of course there is more going on in the conception I defend. Specifically, any object, person or phenomenon positioned in any way i) is practically placed as a component of a totality (so that in my account the term position is not a metaphor $^{2}$ ), ii) usually acquires thereby a specific status, and iii) has certain capacities (already possessed) harnessed to serve as a system function. In the case where human beings are positioned (as components of a community) their capacities are harnessed by way of matched (positional) rights and obligations. The efficacy of the latter in this depends upon not merely the commitment of community participants, or the nature of capacities possessed, but especially their reliability in meeting obligations, and specifically on their being both trusting and trustworthy (so that the latter features are I think reasonably thought of as the glue of social communities).

For the record, I do not deny that propositional representations and so propositional sematic structures with logical relations, and truth conditions etc., are part of the social ontology under study. Nor of course do I deny that deontic phenomena such as obligations motivate action. Nor do I deny a special role for language, even if I am not yet convinced that it is as foundational as Searle supposes. Nor, as just noted, do I suppose that rights and obligations and so system functions (in my terminology) can be performed without collective recognition that some person or thing is appropriately positioned. Nor even do I deny that representations of functions could always be formalised (whether or not they actually are) to conform to the logical form of status function declarations. And I do argue that all human actions (as opposed to doings) 
arepurposeful (and in that sense rational) or intentional under some description (see e.g., Lawson 1997, especially chapter 13), even though the continuous reproduction/transformation of society as a whole is not anyone's intended product.

The features of Searle's account of which I am not yet convinced is that any declaration needs to be involved, or indeed that a language is required, for all positions and associated deontic powers and system functions (Searle's status functions) to prevail. I do not share Searle's intuition that "all deontology requires some form of linguistic representation" (ibid, p. 16). It is for these reasons, I imagine, that Searle concludes that my framework "applies equally to animals and humans" (ibid, p. 2), or in any case is deficient.

In modern communities we learn to think through language, so the question of how essential the latter is to the fact of positions and functions (Searle's status functions) per se is difficult to discern. That is why in my original paper I raised the question of how, for early hominids, language could have emerged without deontology having already been in place. Searle insists that "deontology can only exist if it is in language" believing that a "creature without language cannot operate with obligations". But he thereby admits to being left wondering "How could the linguistic deonticity evolve out of the non-linguistic?", proclaiming this to be "the usual chicken-egg problem" (ibid, p. 18).

In my original piece I argued in effect that there is no chicken and egg problem. Rather deontology would have been present in pre-linguistic collective practices ${ }^{3}$ as a necessary condition for communities to form, the latter themselves being a necessary condition for the emergence of language.

Does my defending such a position prevent me distinguishing human and nonhuman animal societies? If I am wrong in arguing as above, then my position merely reduces to Searle's on these issues, and so I would distinguish human and non-human animal worlds as he does.

But what follows if I am right? Certainly it leaves open the possibility that nonhuman animals may also have a deontology. But this does not mean that I cannot distinguish such animals and humans. Rather, if it is established that non-human animals do possess a deontology, this would mean that the significant difference between humans and other animals lies not in the possession of a deontology per se but in the capacities of humans to form a linguistic deontology. If instead it is established that non-human animals do not have a deontology, this would mean that the significant difference between humans and other animals lies not in the possession of language per se but in the more basic capacities of humans to form a deontology.

Either way, it seems to me that my account of the contrast between human and non-human animal worlds is analytically and explanatorily at least as adequate as Searle's. The difference between us is merely that I do not automatically associate deontology and language. Of course, I do not at all deny that language is a necessary condition for the complex structures of modern society, so that any creature without language could not produce them. My reservations rather relate 
to the presumption that language is essential or foundational in all cases, and to any suggestion that it is ever sufficient.

The basic point, though, is that there is nothing as far as I can see that Searle's account can accommodate that the one I defend cannot. The question, indeed, is whether it can accommodate all that it should do, including, perhaps, how language could have emerged from non-linguistic practices.

\section{THE EXPLANATORY RELEVANCE, AND USE MADE, OF THE NOTION OF EMERGENCE}

The other features of a social ontology that I regard as fundamental but which I believe Searle underplays are those of emergence and social entities.

Relative to his (often repeated) assessment that I take emergence to be an explanatory concept Searle (understandably) finds my brief definitions to be insufficient. But in truth, whilst Searle is right to recognise that I regard the notion of emergence as a central category, I am far from ever interpreting it as explanatory. I can find nothing in my original essay that suggests otherwise. And on the occasions elsewhere that I do explicitly consider the analytical function of the notion, I mostly argue in fact as follows:

\footnotetext{
"So understood the term [emergence] itself indicates nothing about how higher level entities bearing causal powers have come into being. Nor in and of itself does it imply anything about any relationship that might hold between the causal powers of the higher level (emergent) entity and those of its components. Rather the category emergence seems often to serve as little more than a place holder to indicate an incompleteness or gap in the analysis, and specifically an absence of any account of processes whereby unprecedented phenomena occur. It is this gap, I take it, that theories of morphogenesis aim to fill" (Lawson, 2013, p. 62)
}

So, to be clear, I use the term emergence primarily to capture any processes whereby some pre-existing elements become organised into a totality or system, a system that is novel or unprecedented in relation to those elements and their context. In addition, I use the term emergent in reference to the totality itself, its causal properties, and the organisation of the elements. I do also express these developments by saying such novel features somehow emerge. However, the manner in which they do so is always a matter of investigation. None of the terms are interpreted as explanatory.

Most especially, I repeatedly emphasise that uses of the noted terms carry no implications about how the causal properties of any emergent totality relate to those of elements organised as components (see Lawson, 2013 pp,62-3).

That said, I do, in my original piece, express an assessment that forms of reduction are typically in fact proscribed; but I explain why I conclude this, and it is an assessment (to which I return below) that is not part of the definition of emergence. There was a time, I should acknowledge, when I did occasionally slip into tying irreducibility into the definition, and Searle references such a paper 
originally published more than a decade ago. But I have long since worked consistently with the notion given in the passage above, whereby emergence carries within itself no presumption about (ir)reducibility (despite the fact that I continue to believe most emergent totalities are in fact irreducible).

It is really over our answers to questions concerning the possibilities for causal and/or ontological reductions, that Searle and I part company.

Of course, Searle's reply suggests that he does himself connect the notion of emergence to irreducibility. Thus, in arguing, for example, that "artifacts and communities, are not emergent because they are ontologically reducible to their bases" Searle appears to hold that emergence and ontological irreducibility are effectively the same thing, or at least that something is emergent only if it is ontologically irreducible. Consciousness, we are also told, is a real emergent because ontologically irreducible.

But this way of conceptualising emergence, to repeat, is not my own in the current debate, and nor I believe is it typical. Moreover, and interestingly, nor even does it fit with Searle's own previous practice.

Indeed, in previous contributions Searle mainly supports a notion of emergence that allows for both causal and ontological reductions. More specifically, Searle writes of causally emergent system features. These are features of systems that "have to be explained in terms of the causal interactions among the elements". As examples Searle mentions solidity, liquidity, and transparency, though he adds that "consciousness is a causally emergent property of the systems" where the "existence of consciousness can be explained by the causal interaction of the elements of the brain at the micro level [...]" (Searle, 1992, p. 111). And Searle observes that:

"Once a property is seen to be emergent, we automatically get a causal reduction, and that leads to an ontological reduction, by redefinition if necessary" (ibid, p. 116).

Although Searle (1992) does suggest at one point that consciousness may be an exception in that an ontological reduction seems infeasible (p. 116) he eventually qualifies even this assessment:

"Furthermore, when I speak of the irreducibility of consciousness, I am speaking of its irreducibility according to standard patterns of reduction. No one can rule out a priori the possibility of a major intellectual revolution that would give us a new - and at present unimaginable - conception of reduction, according to which consciousness would be reducible" (ibid, p.124, emphasis in the original).

So in his previous contributions Searle too avoids tying emergence to ontological (and/or causal) irreducibility. Of course, differences in our assessments remain, and I shortly turn to these. But for the moment I am merely seeking to free up the category of emergence from the strictures of Searle's current reply (and some of my own earlier practices). With that hopefully achieved I can turn to the issues of substance that seemingly do divide us, and specifically to the question of whether causal and ontological reductions in the social domain are common or the exception. 
My assessment, as already noted, is that many, and likely most of those phenomena, social or non-social, that result from organisation are neither causally nor ontologically reducible. Searle's assessment is the opposite. The crux of our disagreement here is captured within the following passage of Searle's reply:

"What is added to the parts and their organization when the house "emerges"? In [Lawson's] account of the base of the emerging entity, he leaves out the organization of the parts of the house. Why? When the physicist says the table can be reduced to the molecules, he means to include the organization of the molecules. Same with the house. The house is nothing but the parts and their organization. There is nothing in addition that is emergent" (2016, pp. 10,11)

Why do I not consign the organisation of the elements along with the latter to the 'base'? My answer is simply because the organising structure is, and is always, itself an emergent. Whether the focus is on the formation of physical liquids or solids, or social artefacts like houses, bridges, universities, crowds, paintings, or rock concerts, the totality emerges along with, and through the emergence of, its organising structure. When the house or whatever is partly complete so too is this organising structure.

Given Searle's contrasting stance, it is actually not obvious why he distinguishes levels at all. For if, as he suggests, both the organisation and the elements organised are consigned to the base, and there is nothing to a house over and above the organisation and the elements, there is no obvious reason to distinguish a base, when the base is apparently all there is.

Or consider Searle's argument for reducibility by invoking transitivity of causality. Here Searle accepts the premise that "the lower level is causally sufficient for the higher level" (ibid, p.10). But what are the lower and higher levels here? If, to repeat, Searle supposes that the "house is nothing but the parts and their organization" where is the higher level? The elements that become organised as components, or Searle's 'parts', are presumably lower level, so the only candidate remaining to qualify for higher-level status is the organisation. Searle, however, requires that the organisation be allocated to the lower level for the transitivity argument to work. But then once more there is nothing left for any higher level. It is conceivable that Searle is saying that emergent powers exist alone at the higher level. But on what justification, if this level contains neither the entity or entities that bear them, nor any other emergent features?

In any case, I am suggesting that if the terms 'higher level', 'lower level', 'base', 'reduction' and so on are to have any practical relevance, the term 'higher level' refers to all the emergent features, and the terms 'lower level' and 'base' refer to the elements as they exist prior to being organised; and 'reduction' is a conjectured relation between the two. On this conception causal and ontological reductions are proscribed just because the organising structure is part of the emergent level of an organised system. To interpret the organising structure as 
lower level renders the theses of causal and ontological reducibility in most situations trivially true, but at the cost of rendering the most interesting and important part of the explanandum a feature of the explanans, and thereby detracting attention from, rather than to explaining, the phenomena of central interest.

One possible line of reductionist response is to suggest that the emergent organising structure is itself completely determined by the causal interactions of elements which get eventually to form the components of the emergent totality.

But I have shown at length elsewhere that there are very few scenarios where such an argument is even prima facie plausible (see Lawson, 2013). It basically requires that the dynamics of interaction be isolatable (as well as sufficient for emergence). Such conditions are most likely to hold, I have previously argued, where emergence occurs through very simple (non-recursive) forms of dynamics. I have suggested that various surfaces properties of some substances, for example the emergence of surface tension of some liquids, might fit the bill (Lawson, 2013 p. 68). However, even with only slightly more complicated (recursive) dynamics in the physical or non-social realm (such as are involved for example in the formation of the simple snowflake) or, in the social realm, even with very simple (non-recursive) forms of dynamics of emergence (such as in crowd formations) causal interactions of the 'base' or lower level elements are not enough. In such cases, external inputs are always involved and essential. ${ }^{4}$ Of course, the formation of somewhat complex social phenomena, such as cities, universities and capitalism, require correspondingly more complex inputs of external factors. And all artefacts, including the house, require the input of external human beings.

I remain unsure how much of all this Searle would disagree with once semantic differences are resolved. I do not deny the role of collective intentionality in processes of emergence; indeed, I have been explicit about incorporating it elsewhere (see for example Lawson, 2012). But I do think there is more involved. In particular, it is necessary to consider the sorts of factors that influence the form that collective intentionality takes.

POSITIONED (EMERGENT) ENTITIES AND STRUCTURES VERSUS 'FREE STANDING Y TERMS'

If, formally at least, Searle and I do maintain different accounts of the possibility of emergent and irreducible social entities and structures, these differences in turn underpin further contrasts to which I now turn.

The most important arise, to put matters in my own terms, when emergent totalities like communities or aspects of emergent structures are positioned as, and so get to serve, system functions. Not being enamoured with notions of emergent totalities and their structures, Searle, in such cases, has to adopt a different strategy. The one chosen is to employ the notion of 'free standing Y terms' (or empty positions in my terminology), where the functioning of deontic powers 
associated with the Ys (or positions) are somehow achieved merely through their being represented:

"There are examples of institutional facts where the representations are sufficient for the functioning of deontic powers, and where the deontic powers of $\mathrm{Y}$ do not have to be imposed on a previously existing entity as $\mathrm{X}$. These are free standing $\mathrm{Y}$ terms" (ibid, p. 18).

Let me again consider the most significant cases of the corporation and money, both of which are interpreted by Searle as examples of free standing Y terms.

\section{THE CORPORATION}

Actually I am not sure there is much to add here to my original argument concerning the nature of the corporation. Searle's reply seems to focus upon, and take issue with, only an aspect of my claim, namely that a relevant community exists before being positioned/constituted as a corporation. Thus Searle is keen to point out that, in California anyway, a corporation can legally be formed out of nothing, created merely by ‘filing articles of incorporation', with no community in sight.

In truth, if this is indeed so, though I remain not wholly convinced, it does not affect my basic argument. For I insist only that some entity must be positioned as a corporation soon enough if its system (i.e., industry-wide) function is ever to be performed. The latter I take it is the coordinated production of goods and/or services to be sold to others, in a way that is intended to be advantageous to (at least some of) the community members, with (at least some of) that advantage interpreted as 'profits' (see Lawson, 2015). My claim is simply that the function cannot be served without a community acceptance of an appropriately relationally organised group of people qua community being suitably positioned.

Let me turn to Searle's response to my comments on money.

\section{Money}

Money, I maintain, is a form of value. It is specifically an individual form that is accepted throughout a community as having been positioned as a general form of value, thereby gaining the status of 'money', and also coming to serve the system function of a general means of payment.

In modern societies, the form of individual value so positioned is typically bank or state-backed debt. The holder of the debt is in a relation of credit/debt or of right/obligation with the issuer of the debt. Items like cash (notes and coins) are positioned identifiers of this debt relation. They are markers or tokens. In the opening paper I also mentioned they are essentially material IOUs, which I also take to be markers of debt relations. 
Searle thinks such a view to be very 'strange'. Let me take his basic response in steps. Searle firsts asks:

"If the twenty dollar bill is really an IOU, then I ought to be able to cash the IOU and get some real money" (ibid, p. 19).

But the holder of the bill already holds 'real money'. The bill marks the holder of the money. Modern money is simply state-backed debt appropriately positioned.

Searle continues:

"I ought to get the government to pay the debt promised to pay on the twenty dollar bill. But there is nothing the government can do except hand me another twenty dollar bill” (ibid, p. 19).

If Searle wants the issuer of the debt to redeem it, this may be possible but this actually involves Searle giving up, rather than acquiring, real money. In this Searle will typically have to choose amongst the sorts of things that lie within the jurisdiction of the bank or state to provide. He can certainly use some of his bank credit to discharge his own debt to the state, the later perhaps taking the form of taxes due, fines to be paid, purchases of alternative more 'risky' (less liquid) non-monetised forms of government debt and so on. Searle may in fact choose to invest his money in stocks and shares purchased on his behalf by his bank, i.e., in a variety of nonmonetised credits or debts. In all such cases, the bank's debt to Searle might be said to be redeemed or discharged. But I repeat that, in all such ways, Searle has not only not acquired real money but has actually given it up.

Of course, in practice if Searle goes to a bank and hands over a twenty-dollar bill, the bank's response will more than likely be to add an entry of twenty dollars to the bank's electronic record of Searle' money holdings. In this case the transaction by itself would not affect the amount of money in Searle's possession though it would reduce his holdings of cash.

Searle next adds:

"It used to say on the bills that the government would "pay the bearer" twenty dollars on demand, but that is a leftover from the gold standard when there was actually a promise to redeem paper money in gold coins. Those days are gone" (ibid, p. 19).

Searle thus takes it for granted that to exchange cash for gold coins is to exchange it for something very different, and perhaps even a way of redeeming any promises written on the notes. But even this assessment is controversial. There are not many economists who spend time considering the nature of money, but there are some. There are also numerous anthropologists and sociologists that do. It may then perplex Searle to learn that the dominant view amongst this group is that money was always debt, and that even gold coins were essentially markers of this debt-money employed in eras where the technology for producing counterfeit-proof paper markers was unavailable (see for example Innes, 1913, pp. 391-2, or Ingham, 2004). 
Finally, Searle includes some interesting additional remarks about the money of ancient Sparta:

\footnotetext{
"At one point in ancient Sparta, the community used heavy iron bars as money. The reason apparently was that the authorities did not want people to be able to take money out of the city. The point is that you can use heavy iron bars as money but their money character is not already part of the iron" (ibid, p. 20).
}

The money character is certainly not part of the iron or of anything else that happens ever to be positioned as money. On this we agree. The character of money is acquired only by positioning something of value as the general form of value (whereby it gets to serve as a general means of payment), and becomes thereby an attribute of the positioned thing, not of the thing positioned.

So the point is that if indeed such iron bars served as features of a monetary system -- and there is not actually much, if any, archaeological evidence, as opposed to legend, such as Plutarch's 'The Life of Lycurgus' would have been (the positioned) value items. Even iron has value. As the legend of Plutarch has it, in so replacing gold and silver by these iron bars, the result was a reduced value per unit weight (so that any object that could previously be purchased with a small piece of silver now required, large quantities of the positioned iron). In consequence, various uses of money would have been rendered more difficult, including indeed any that depended on the ability to transport it from the city, and as would robbery of money.

Of course, credit theorists, would presumably argue that any such bars were not money at all but merely tokens of some form of debt, with only the latter being an item of value positioned and so serving as money.

Whichever is the correct interpretation, I see nothing that challenges my own account of money here. In ancient Sparta as elsewhere, money (whether taking the form of positioned iron or debt, or indeed gold or silver) would have been constituted through community acceptance of an individual form of value being positioned as a general form of value.

\section{FURTHER COMMENTS AND CONCLUSION}

My assessment, in summary, which no doubt also raises as many issues as it seeks to resolve, is really quite simple. Searle and I have conceptions of social ontology which, though stated in different terminologies, have much in common. My worry about Searle's conception is mainly that it does not go far enough. Specifically, for whatever reason, Searle has so far failed to elaborate sufficiently explicitly an account either of collective practices other than linguistic ones or of emergent social totalities and their equally real organising structures (that I believe his conception presupposes). It is the latter set of relative absences especially that underpins his adopting (I believe erroneously) the notion of 'free standing Y terms' 
for cases where simple solid physical bearers of de-ontic powers are not in evidence. I repeat, though, that these limitations of Searle's account, if such they are, are easily rectifiable, representing, at least in their basics, essentially an error mostly of omission, or, perhaps more accurately, a reluctance explicitly to systematise features that seem necessarily to be presupposed.

\author{
Tony Lawson, \\ Faculty of Economics Sidgwick Avenue, \\ Cambridge CB3 9DD. \\ E-mail:Tony.Lawson@econ.cam.ac.uk
}

\title{
NOTES
}

1 Searle is unconvinced by my conception of the social realm, appearing to regard it as too inclusive, encompassing, he supposes, "the influenza epidemic of 1918" (Searle, 2016, p. 13). The notion does allow that entities like, say, gardens and zoos are social, in that the relational organisation of each, and so the totality -- but not the animals or plants that are organised as components -- necessarily depend for their existence on us. Wars too are comprised of organised communities interacting in accord with at least some common rules of engagement. But pandemics or epidemics of viruses are not forms of social organisation as I define these terms (but merely a type of virus occurring in large numbers), and neither viruses themselves nor pandemics or epidemics of viruses, depend necessarily on us for their existence.

${ }^{2}$ I do not, though, accept Searle's supposed literal interpretation of position as spatial location. The (Latin and French) etymology of the term associates the term with (amongst other things) placement and arrangement but not necessarily with spatial features. The latter is but a special case.

${ }^{3}$ I do not actually use the term social practice, only collective practice. As I have elsewhere argued: "To be a practice I take it is to be a way of proceeding or going on that is actually pursued or followed. Here the emphasis is on both a way of proceeding as well as on the fact of it actually being followed. [...]" And a "collective practice [...] is collective not in relation to who, or to the unit that, performs it, but in that within the community it is an accepted or done way for an individual or a group to proceed to reach a particular end in a given context. As such it is a practice that in effect has the status of being accepted as legitimate for the circumstances within the community" (Lawson, 2016). In short, it is a practice accepted throughout a community as a positioned practice, one that carries a deontology within it. So community participants (or a subset) have a right to partake and an obligation to do so in certain accepted ways, and a right to expect others to do so in the same ways.

4 The snowflake forms as a result of its trajectory through the air where it is subject to collisions and variations in temperature, vapour supply and so on (Lawson 2013, pp. 74-5). Crowd formations draw upon pre-existing (if variable) conventions concerning ways of interacting with strangers, including distance between bodies, forms of conversation, and so on. The emergent outcome will vary according as to whether the crowd is on a pilgrimage to Mecca, going to or from a football game or rock concert, demonstrating against the government and so on (Lawson, 2013, pp. 69-70). 
5 At one point Searle writes:

"The existence of artefacts such as houses is causally explained by the conscious efforts of builders" (ibid, p. 13)

This is certainly so. But whatever else this shows, it is clear that the organising structure of the house is not determined by the causal interactions of the components (the bricks, mortar, cement, panes of glass, etc.) alone; the builders are also required.

${ }^{6}$ Certainly, the surrounding corporate governance literature as well as consultants' advice and guidance on forming corporations in California appear uniformly to indicate that filing articles of incorporation is not nearly sufficient. The following observation is indicative and to the point:

"Articles of Incorporation are filed with the California Secretary of State to start the incorporation process. This is the beginning of forming a corporation, but it doesn't provide structure to the entity. When you form a corporation in California you have to adopt bylaws, appoint directors, execute an Organizational Action, elect officers, issue shares and undertake more steps discussed below. There is a huge difference between 'filing Articles of Incorporation' and 'forming a Califormia Corporation"'. Downloaded on February 212016 from: http://www.paralegal-plus. com/california-incorporation.php (emphasis in the original).

7 See Plutarch's Lives, Lycurgus, downloadable from http://penelope.uchicago. edu/Thayer/E/Roman/Texts/Plutarch/Lives/home.html on 21/02/2016

\section{REFERENCES}

Ingham, G. (2004). The Nature of Money, Cambridge: Polity Press.

Innes, A.M. (1913). 'What is Money?' Banking Law Fournal, May, p. 377-408

Lawson, T. (1997). Economics and Reality, London and New York: Routledge.

Lawson, T. (2012). Ontology and the Study of Social Reality: emergence, organisation, community, power, social relations, corporations, artefacts and money, Cambridge fournal of Economics, vol. 36, no. 2, 345-385.

Lawson, T. (2013). Emergence, Morphogenesis, Causal Reduction and Downward causation, in Margaret S.A. (ed.). Social Morphogenesis, New York: Springer, pp. 61-84.

Lawson, T. (2015). The Nature of the Firm and Peculiarities of the Corporation, Cambridge Fournal of Economics, 39, 1-32.

Lawson, T. (2016). Collective Practices and Norms, in Archer, M. (ed.) (2016), Morphogenesis and Normativity, New York: Springer.

Searle, J.R. (1992). The Rediscovery of the Mind, Cambridge, MA, MIT Press.

Searle, J.R. (2016). The Limits of Emergence: Reply to Tony Lawson, Fournal for the Theory of Social Behaviour (forthcoming) 